\title{
Structural Stability Analysis of High Pile Wharf under Dynamic Load
}

\author{
Li Bin $^{1} 2$ 3,a Xu Weiwei ${ }^{4}$ \\ ${ }^{1}$ Tianjin Port Engineering Institute Ltd. CCCC First Harbor Engineering Company Ltd., Tianjin, \\ China
}

${ }^{2}$ Key laboratory of port geotechnical engineering, ministry of communications, PRC.Tianjin, China

${ }^{3}$ Key laboratory of port geotechnical engineering of Tianjin.Tianjin, China

${ }^{4}$ College of Civil Engineering, Hebei University of Engineering, Handan 056000, China)

a lee binbin@163.com

Key words: High-pile Wharf; load; stress stability;

Abstract. A heavy equipment wharf intends to ship11100 tons "upper part of self-elevating offshore platform ", the offshore platform located in the rear of the wharf base terminal yard, adjacent to the pile platform. The finite element software ABAQUS is used to analysis of the "upper part of structure" stress, deformation and stability of heavy equipment wharf when shipped from terminal yard to the sea. Results showed that only under its own gravity and pile wharf, pile cap, slide stress are much lower than the design strength of the material and the displacement were not more than $1 \mathrm{~mm}$, but in sliding area, different types of cap expansion joints and near cloud rail are stress concentration degree is serious, force has exceeded the material yield strength. The results of calculation for modify the plan of the shipment platform and provide reference data of transportation security, and put forward the corresponding suggestions.

\section{Introductions}

The high-piled wharf is a common and important form of structure, Pile wharf has a wide range of applications because of its simple structure, light weight, less reflection of waves, which can withstand large loads and suitable for soft soil foundation, and so on in coastal areas of China and the Yangtze River. Pile wharf not only bear the vertical load, more importantly, bear the horizontal load, such as the wharf shipped, the ship impact, etc., and with the level of dynamic load uncertainty and sudden, the dynamic response to the pile and pile structure is natural more difficult to grasp and predict than the static response generated by the static load. So to some extent, the dynamic load of level is much more harmful than the static load.

The project is intended to be a reloading base wharf to be shipped "self-elevating offshore platform of the upper structure. In order to analyze the "upper structure of the jack-up offshore platform", the force, deformation and displacement of the wharf structure, as well as the modification and safe shipment of the platform, are provided with reference data during the process of dragging 15000t of the heavy wharf. In this paper, the large-scale finite element analysis software ANSYS to analysis the safe use of the wharf structure of platform in the process of dragging, and the corresponding transport programs and cloud structure reinforcement program requirements.

\section{Project Overview}

The 15000t slide of the wharf and the layout of the wharf are shown in Figure 1, cloud rail is not direct contact with top surface of the pier concrete, but rather a layer of steel at the top of the wharf platform and the thickness of the steel plate is about $1.2 \mathrm{~mm}$. The total weight of the offshore platform is $11,100 \mathrm{t}$, the transport used to carry the truck for 46 units, the average load of each truck can carry 400t, from the rear yard cross the rail transport to reach the forefront of the pier and outfitting transport. 


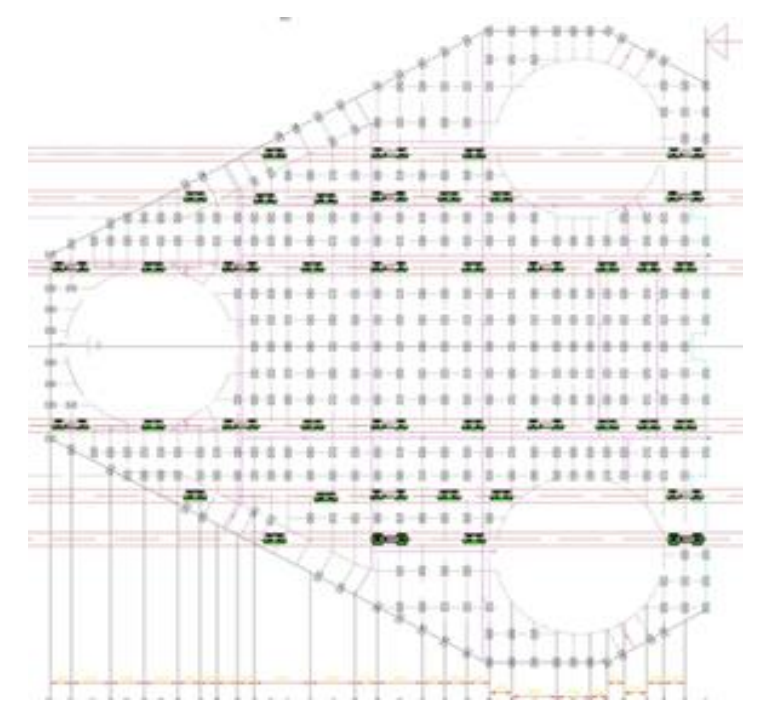

Fig. 1 Wharf layout chart

\section{Model Simulation}

Take wharf structure for of a section of the object, the establishment of finite element calculation model is shown in figure 2. The engineering model in accordance with the actual project data of wharf, take the wharf width of $25 \mathrm{~m}$, length $79 \mathrm{~m}$, vertical divided into steel plate layer $0.2 \mathrm{~m}$, wear layer $0.1 \mathrm{~m}$, cast-in-place pier $2 \mathrm{~m}$, plain concrete $1.3 \mathrm{~m}$. The pile foundation in front pile table adopts $0.65 \mathrm{~m}$ prism length, Steel plate and wear layer, Reinforced concrete layer, between the Concrete layer and ground layer are using binding constraints, the pile is in contact with the foundation in order to simulate the force of the actual pile foundation and the friction between the materials.

Do not consider the top of the pier embedded I-beam, so biased conservative, but the results are biased towards safety. The value of pile length in finite element model is calculated by hypothetical embedded point method, without considering the articulation of the force between the platform, the horizontal forces between the different pedestal sections are transmitted through the chute. The horizontal force caused by the friction between the top of the truck, the rail, and the platform. The integrated friction coefficient of the truck chain roller is taken as $\mu=0.05$, the average acceleration of the truck is $0.002 \mathrm{~m} / \mathrm{s}^{2}$. According to the principle of maintaining the same bending stiffness, the equivalent of the steel box girder structure is equivalent to a solid steel plate equivalent thickness of $62 \mathrm{~mm}$, width of $1100 \mathrm{~mm}$.

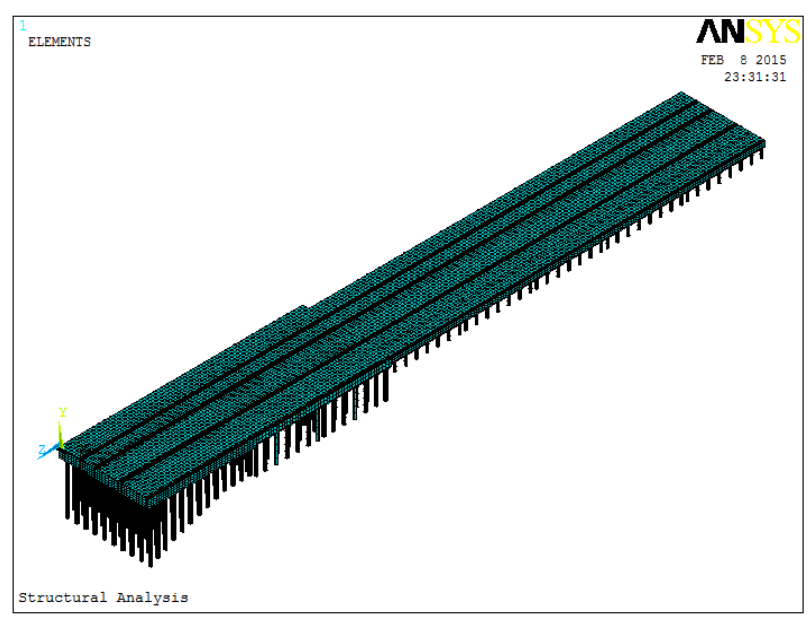

Fig. 2 Finite element calculation model chart 


\section{Analysis of Simulation Results}

The finite element method is used to analyze the stress, deformation and displacement of the $15,000 \mathrm{t}$ chute structure under the three factors: (1) weight, (2) weight + vertical force, (3) weight + vertical force + horizontal force. Where the position of the vertical force and the horizontal force on the rail corresponds to the position of the truck on the slide. The results are shown in Table 3, and the stress and strain clouds are shown in Figure 3.

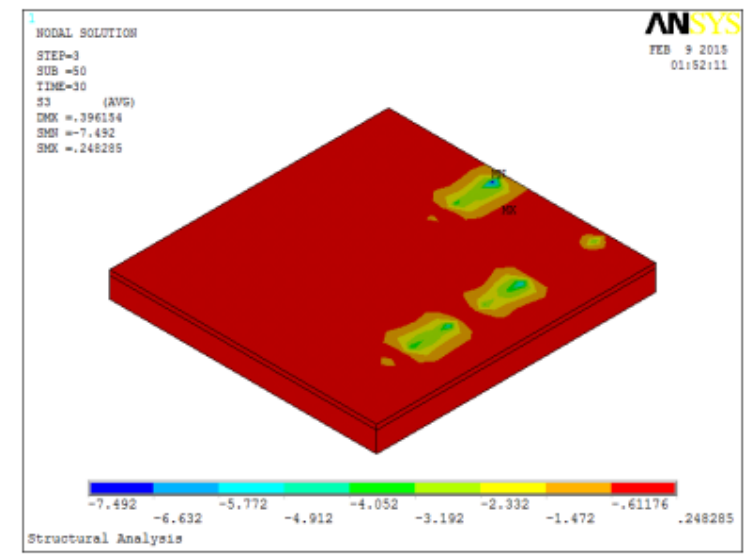

Fig. 3 Main compressive stress of platform

When only bear their own gravity, the pile foundation, bearing platform, slide stress are much lower than the design strength of the material, the displacement of the three were not more than $1 \mathrm{~mm}$; Under the action of self - weight and vertical force, the main tensile stress of pile foundation under different pile tables is less than the design value of axial tensile strength of pile body concrete, pile displacement are also not more than $1 \mathrm{~mm}$, which pile vertical pressure, the vertical displacement is obviously larger than the displacement of the other two directions;

Under the action of self-weight and vertical force, in the platform covered by the slide area, different platform between the expansion joints and the nearby cloud rail, as well as the adjacent two vertical force between the role of the cloud rail, the stress concentration is serious, the stress size has exceeded the yield strength of the material;

Under the action of self-weight and vertical force, in the platform covered by the slide area, in the pile at the expansion joints at the concrete, the main tensile stress is greater than the design of the concrete tensile strength, the main compressive stress is greater than the design of concrete axial compression strength of the situation, and the concrete at the expansion joints has the risk of being cracked or crushed.

Under the action of self-weight and vertical force, in the platform covered by the slide area, different platform between the expansion joints, as well as the nearby clouds and the adjacent two vertical force between the role of the cloud, stress concentration is serious, and the stress size has exceeded the yield strength of the material;

Under the action of self - weight, vertical force and horizontal force, the horizontal displacement of pile foundation increased slightly, but the change of principal stress was not obvious.

Under the action of the surface force load, the displacement of each node on the foundation and foundation is zero. The calculated results show that the stress increases with time, which is in accordance with the general calculation of finite element calculation, but does not exceed the compressive strength of concrete, so the structure is stable.

\section{Conclusion and Suggestions}

(1) Calculation under different constraint conditions, cloud rail under the action of vertical force and horizontal force of the stress and deformation, as increasing the rail section compressive stiffness and bending stiffness of basis; 
(2) When the truck passes, there is a risk of cracking or crushing of the concrete at the expansion joints of the platform, so reinforcement measures or decentralized loads should be considered.

(3) Under the action of self-weight, vertical force and horizontal force, the response of the platform and the cloud rail is basically the same as that under the action of self-weight and vertical force.

\section{References}

[1] AMERICAN PETRALEUM INSTITUTE. Recommended practice for planning, designing and constructing fixed offshore platforms [M]. API Recommended Practice 2A-WSD (RP2A-WSD), 2000, 21st ed.

[2] YAN L, BYRNE P M. Lateral pile response to monotonic pile head loading [J]. Canadian Geotechnical Journal, 1992, 29: 955-970.

[3] KIM B T, KIM N K, LEE W J, et al. Experimental load-transfer curves of laterally loaded piles in Nak-Dong River sand[J]. Journal of Geotechnical and Geoenvironmental Engineering, 2004, 130(4): 416-425.

[4] ASHOUR M, NORRIS G. Modeling lateral soil-pile response based on soil-pile interaction [J]. Journal of Geotechnical and Geoenvironmental Engineering, ASCE, 2000, 126(5): 420-427.

[5] REESE L C, MATLOCK H. Non-dimensional solutions for laterally loaded piles with soil modulus assumed proportional to depth[C]// Proceedings of the 8th Texas Conference on Soil Mechanics and Foundation Engineering. Austin: Bureau of Engineering Research, University of Texas, 1956. 